\title{
РАЗВИТИЕ ЭЛЕКТРОННОЙ КОММЕРЦИИ В МИРОВОЙ ЭКОНОМИКЕ И В КАЗАХСТАНЕ С УЧЕТОМ ПАНДЕМИИ COVID-19
}

\author{
(C) 2021 Кожахметов Жанат Амангельдыевич \\ магистрант кафедры экономики \\ Атырауский государственный университет им. Х. Досмухамедова, Казахстан, Атырау \\ E-mail: zhanzhan2@gmail.com \\ (c) 2021 Дюсегалиев Мухит Жоламанович \\ доктор сель.хоз. наук, ассоц. профессор кафедры экономики \\ Атырауский государственный университет им. Х. Досмухамедова, Казахстан, Атырау \\ E-mail:mukhit-65@mail.ru \\ (c) 2021 Утепкалиева Кансулу Мусаевна \\ кандидат экономических наук, и.о. ассоц. профессора, проректор по учебной работе \\ Атырауский государственный университет им. Х. Досмухамедова, Казахстан, Атырау \\ E-mail: k.utepkaliyeva@asu.edu.kz
}

В данном исследовании оцениваются мировые показатели электронной коммерции и темпы роста стран-лидеров в этой сфере. Рассмотрены предпосылки для развития электронной коммерции в этих странах. Наряду с рассмотрением развития электронной торговли во всем мире, так же эти данные сравниваются с развитием данной отрасли в Казахстане. Выясняются причины, сдерживающие своевременный рост электронной торговли Казахстана, и рассматриваются пути их устранения.

При изучении темпов развития электронной коммерции мы также учитывали влияние пандемии COVID-19. Выявлено состояние электронной коммерции после снятия ограничений, связанных с пандемией, и причины его возврата в прежние темпы развития.

Эти исследования проводились путем всестороннего сравнения и анализа данных об электронной торговле. В ходе исследования были выявлены причины отставания Казахстана в этой сфере, такие как правовые барьеры и низкие темпы развития инфраструктуры необходимой для электронной коммерции. Под инфраструктурой мы понимаем низкое качество услуг доставки, сложность процесса возврата товара, высокий уровень цен на услуги доставки.

Ключевые слова: Электронная коммерция, служба доставки, интернет-магазины, пандемия, онлайн покупатель.

\section{Вступление}

Последние 20 лет электронная коммерция стремительно развивается во всем мире. Если в 2014 году на долю электронной торговли приходилось $10,5 \%$ мировой розничной торговли, то в 2020 году этот показатель составлял 16,5\%, а по прогнозам бюро статистики Statista, в 2023 году на электронную торговлю будет приходиться $22 \%$ всего объема розничной торговли в мире [1]. Однако, несмотря на стремительное мировое развитие, развитие данной отрасли в Казахстане оставляет желать лучшего. Так, в 2014 году только $0,65 \%$ всей розничной торговли в Казахстане приходилось на электронную коммерцию, а в 2019 году доля электронной коммерции составляла всего $1,8 \%$ [2]. Это очень низкий уровень по сравнению с развитыми странами мира. Поэто- му, чтобы попасть в список стран-лидеров и не отставать в развитии, Казахстану необходимо выявить сдерживающие факторы и выработать план для успешного развития электронной коммерции.

История электронной коммерции: О времени появления электронной коммерции нельзя сказать наверняка, потому что сегодня электронная коммерция - это продажа и покупка товаров и услуг через Интернет. Однако даже до появления Интернета можно было покупать услуги и товары с помощью средств связи. Например, в 1960 году American Airlines учредила дочернюю компанию Sobre Corporation, через которую внедрила систему автоматического бронирования авиабилетов. Этого он достиг через сотрудничество с IBM [3]. И торговые отношения, осущест- 
вляемые с помощью таких средств связи, начали очень быстро развиваться с появлением Интернета. Согласно приведенной ниже диаграмме (рис. 1), в 2015 году на электронную торговлю приходилось 7,4\% мировой розничной торговли, а в 2020 году - 16,5\%. Другими словами, доля электронной коммерции в мировой розничной торговле растет умеренными темпами ежегодно, и за последние пять лет с каждым годом объем электронной торговли увеличивается в среднем на $20 \%$ [4].
Для такого роста есть несколько предпосылок, такие как развитие платежной системы, развитие служб доставки, развитие Интернета и рост цифровой грамотности населения.

Давайте рассмотрим причины, по которым потребители выбирают электронную коммерцию, на основе аналитического отчета консалтинговой компании KMPG International. Coгласно данным анализам, основная причина, по которой покупатели совершают покупки в Интернете, - это удобство. Другими словами,

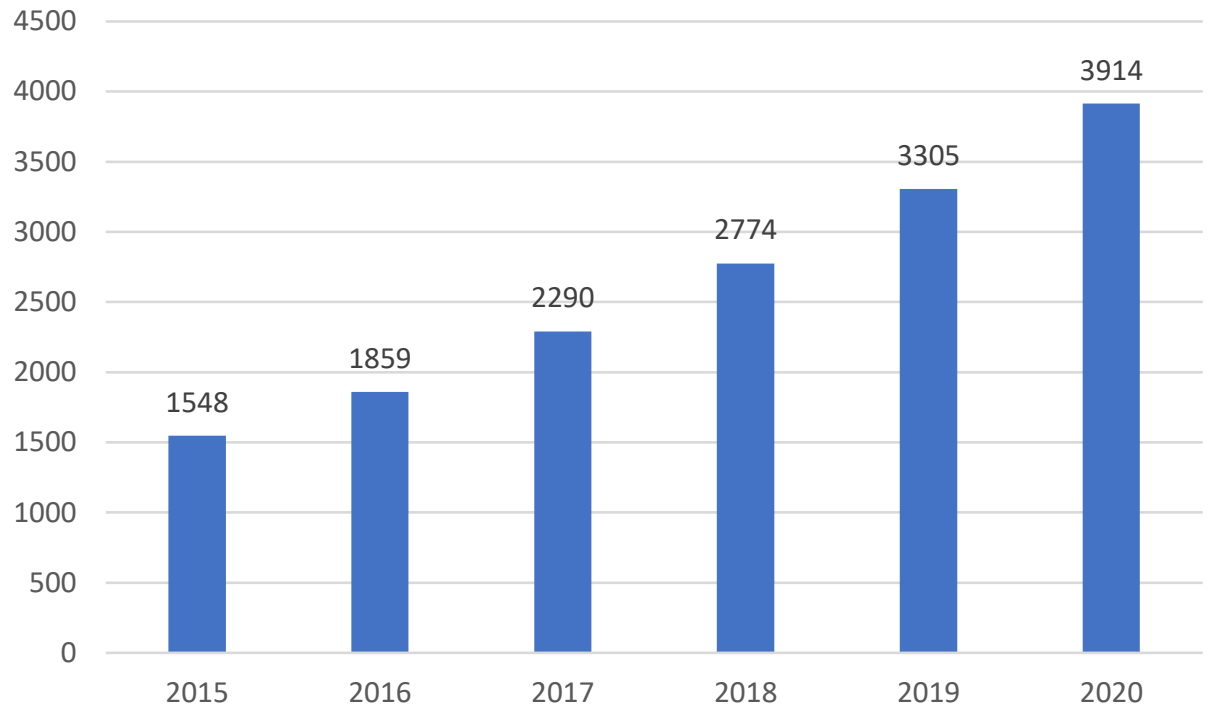

Puc. 1. Объем продаж электронной торговли в мире 2014-2020 гг. (трлн. долларов) [1]

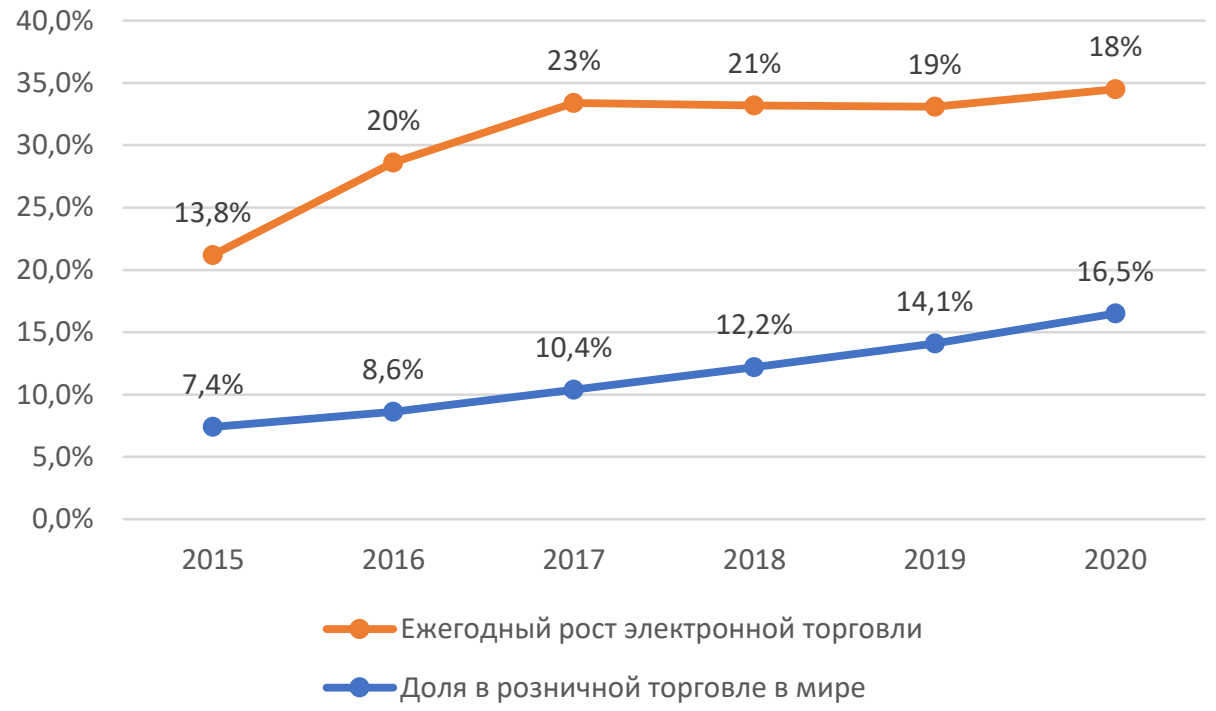

Puc. 2. Доля электронной торговли в общем объеме мировой различной торговли. Объем ежегодного роста мировой электронной торговли [4] 
покупатели отметили преимущества покупок 7 дней в неделю, 24 часа в сутки, возможность сэкономить время, возможность найти все необходимые товары в одном месте. Вторая причина выбора покупок в Интернете - это низкая цена или возможность сравнивать цены [5].

Как электронная коммерция может предоставить такие возможности?

Поскольку электронная коммерция осуществляется через Интернет, покупатели могут делать покупки находясь где угодно и когда угодно. В то же время, поскольку интернет-магазины и торговые площадки демонстрируют товары в Интернете, нет необходимости содержать физический офис и точки продаж, что приводит к более низким ценам [6]. Так же электронная коммерция сокращает географическое расстояние и делает доступными новые продукты и технологии [7].

Приведенная ниже диаграмма (рис. 3) показывает годовую динамику роста стран с развитой электронной коммерцией в мире. К этим странам относятся Великобритания, США и Китай. С 2014 по 2020 годы в этих странах электронная коммерция развивалась быстрыми темпами. Если в 2014 году доля электронной торговли в розничной торговле Великобритании составляла $11,2 \%$, в США 6,5\%, в Китае 10,6\%, то в 2020 году эти показатели выросли более чем 2 раза [8] [9] [10]. В последнее время мы можем заметить стремительный рост электронной торговли Китая. Это связано с тем, что большинство выставок производственных товаров переходят на электронный формат.

Так же одним из факторов, влияющих на развитие электронной коммерции в Китае, является поддержка со стороны правительства. В последние годы активно поддерживаются развитие новых форм электронной коммерции в Китае. Например, 25 марта 2020 года Торговое бюро Ганьчжоу приняло план действий по развитию электронной коммерции в Ганчжоу. Это мероприятие, предназначенное для обучения квалифицированных менеджеров по продажам в сфере электронной коммерции. А 22 мая 2020 года в Цзинане официально вступил в силу «План по эффективному осуществлению развития экономики электронной коммерции и созданию экономической базы для прямых продаж». Этот план был разработан для создания международной базы электронной коммерции. Конечно, есть много факторов, влияющих на развитие электронной коммерции, но мы видим, что поддержка со стороны государства дает неоспоримые результаты развития [11].

Влияние Пандемии Covid-19 на электронную коммерцию развитых стран. 11 марта 2020 года Всемирной Организацией Здравоохранения была объявлена Пандемия Covid-19. В связи с этим повсеместно начали вводится карантинные действия ограничивающие свободное передвижение людей. В результате данных действий во 2 квартале 2020 года мы можем увидеть кардинальные изменения в электронной коммерции. На диаграмме (рис. 4) мы видим, как пандемия covid19 повлияла на электронную коммерцию в США и Великобритании. Если посмотреть на темпы развития электронной коммерции в США, то в 1 квартале 2018 года этот показатель составлял 9,4\%, в первом квартале 2020 года - 11,8\%, то есть темпы роста незначительны. Во втором квартале 2020 года этот показатель резко вырос до 16,1\%. Точно так же, если

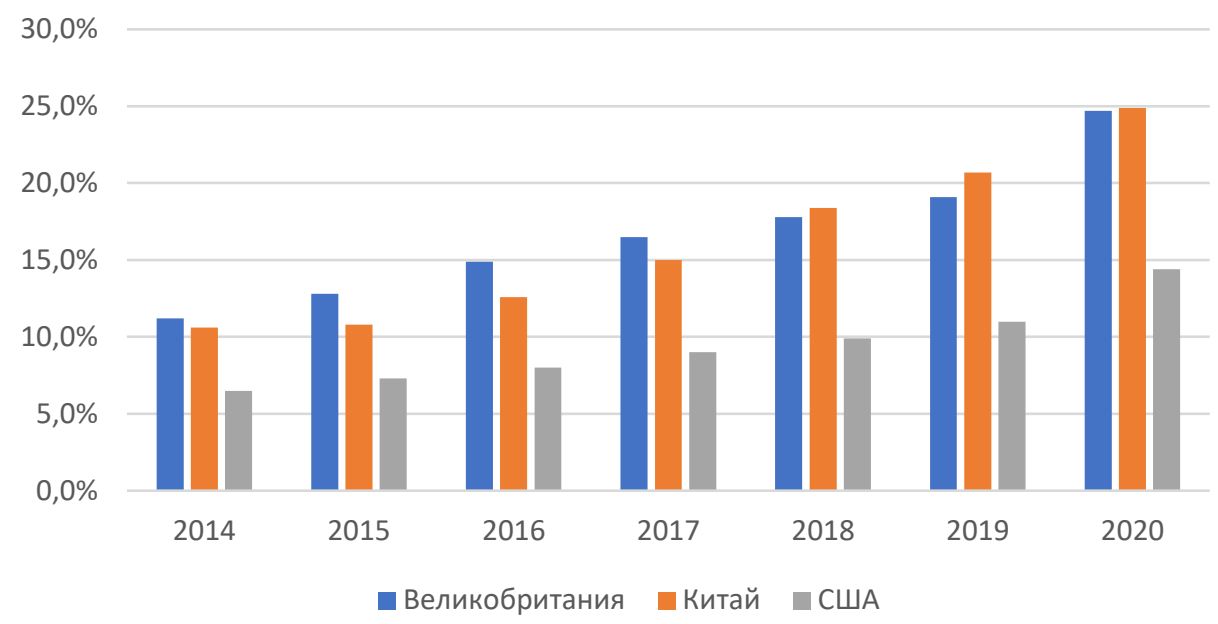

Puc. 3. Доля электронной торговли в розничной торговле товаров в лидирующих странах мира [8] [9] [10] 


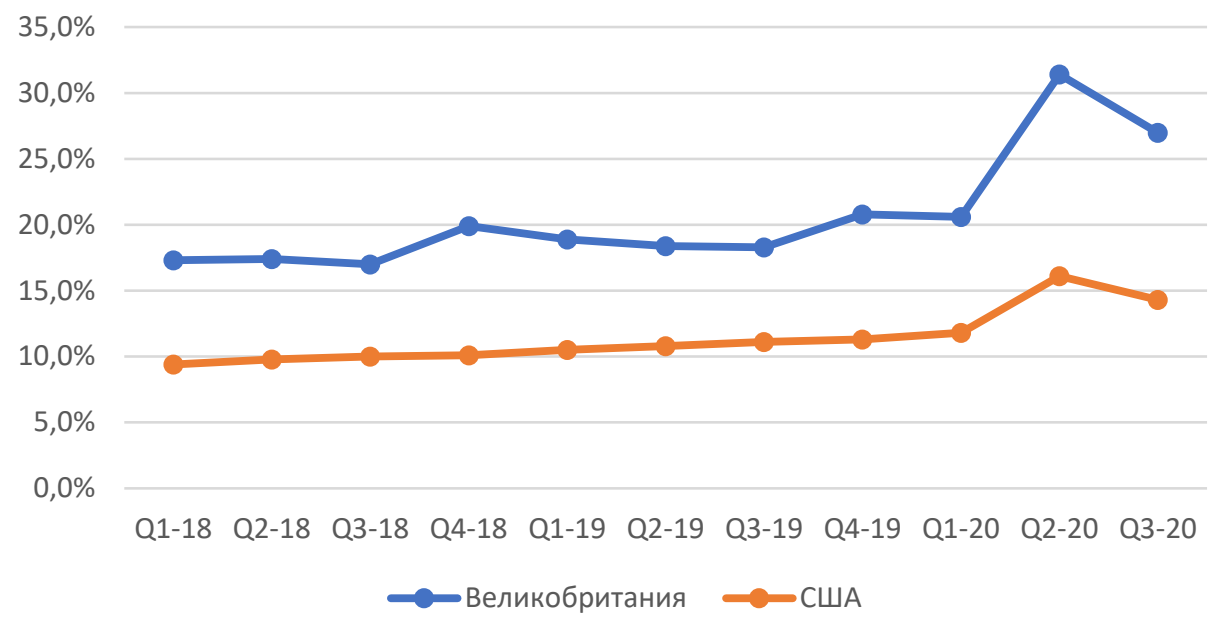

Puc. 4. Квартальные показатели доли электронной торговли в Великобритании и в США [10] [12]

мы посмотрим на электронную коммерцию в Великобритании, доля электронной коммерции в первом квартале 2018 года составила 17,3\%, а в первом квартале 2020 года - 20,6\%. То есть 3-х годовой рост происходит плавно, без резких скачков. Но во втором квартале 2020 года мы видим, что уровень электронной коммерции в Великобритании резко вырос до 31,4\%. Конечно, эти изменения были связаны с тем, что из-за пандемии covid19 люди не могли передвигаться так же свободно, как раньше. По этой причине людям приходилось делать необходимые покупки через Интернет.

В результате пандемии изменилась и корзина покупок в Интернете. Например, согласно отчету консалтинговой компании KMPG International, до пандемии покупатели покупали в основном предметы роскоши в Интернете [5], а во время пандемии люди в первую очередь покупали предметы первой необходимости. В Германии покупатели через интернет в основном покупали лекарства и продукты. В Корее основную долю онлайн-торговли пришлось на долю общественного питания, товаров для дома, продуктов питания и напитков. Доля таких отраслей, как культурные развлечения и путешествия, которые имели высокую долю в онлайн-торговле до пандемии, значительно снизилась во время пандемии [13].

Развитие электронной коммерции в Казахстане и влияние Пандемии Covid-19.

За последние несколько лет электронная коммерция в Казахстане развивается хорошими темпами. Другими словами, среднегодовой темп роста за последние 6 лет составляет 35\%. Доля электронной коммерции в 2014 году соста- вила $0,65 \%$ от внутренней розничной торговли, а в 2019 году - 1,8\%. За 6 лет этот показатель увеличился в три раза. А в 2020 году из-за пандемии уровень электронной коммерции составил около 4\% [2]. Несмотря на положительные темпы роста, уровень электронной коммерции в Казахстане намного ниже, чем в ведущих странах мира. Поэтому одних рыночных инструментов для развития электронной коммерции недостаточно. Без правовой помощи со стороны государства будет очень сложно исправить такую критическую ситуацию. Для этого было принято решение об освобождении от налогов предприятий, реализующих товары через интернет. Данные льготы действуют с 1 января 2018 года по 2023 год [14]. В Казахстане зарегистрировано более 2000 интернет-магазинов. Однако, несмотря на эти льготы, только 579 из этих предприятий смогли получить к нему доступ [15]. Это указывает на то, что существует ряд административных барьеров для доступа к льготам.

Влияние пандемии на электронную торговлю в Казахстане.

В связи с пандемией Ковид-19 с 16 марта по 11 мая 2020 года в стране была введена чрезвычайная ситуация и объявлен карантин. Даже после снятия ограничительных мер люди избегали места массового скопления людей из-за страха заразиться вирусом. Таким образом, возможности торговли обычными средствами были ограничены. В результате во втором и третьем кварталах 2020 года объемы электронной коммерции выросли в несколько раз. Если объем электронной коммерции за 9 месяцев 2019 года составила 198 миллиардов, то в 2020 году объем 
электронной коммерции за тот же период составила 382 миллиарда, увеличившись на 93\%. Объем электронной коммерции в первом квартале 2020 года составила 84 миллиарда, а в третьем квартале того же года - 186 миллиардов, увеличившись на 121,4\% по сравнению с первым кварталом. Пандемия ускорила процесс адаптации покупателей к электронной коммерции, что стимулировало розничных продавцов товаров переключиться на электронную коммерцию [16].

Однако из диаграммы (рис. 4) можно заметить сокращение доли электронной коммерции в третьем квартале 2020 года после снятия ограничений в США и Великобритании. Это показывает, что покупатели вернулись совершению покупок традиционным способом. Почему покупатели не сохранили привычку делать покупки в Интернете, выработанную во время пандемии? Основные причины, по которой потребители отказываются покупать в Интернете связаны с качеством и стоимостью доставки. Опрос, проведенный в США в 2019 году, показал следующий результат: 17\% потребителей всегда отказыва- лись от покупки, если не было бесплатной доставки. 28\% часто отказываются от покупки если нету бесплатной доставки, и $23 \%$ отказываются покупать примерно в одном из двух случаев. Как видите, время доставки и стоимость доставки очень важны для онлайн-покупателя [5].

В заключение, очевидно, что пандемия в Казахстане стимулировала электронную торговлю. Но несмотря на временные позитивные изменения существует множество факторов, которые отталкивают потребителей от покупок в Интернете. Из более чем 2000 упомянутых интернетмагазинов только 579 получили скидки [15]. Это напрямую влияет на цену онлайн-продаж. Поэтому властям Казахстана нужно работать над устранением преград развития электронной коммерции. Второй упомянутый фактор - это качество услуг доставки. Чтобы улучшить качество данной услуги, необходимо обеспечить максимальную поддержку и льготы предприятиям, работающим в сфере доставки и логистики.

\section{Библиографический список}

1. Global retail e-commerce sales 2014-2023 Published by Tugba Sabanoglu, Nov 30, 2020 // URL: https://www. statista.com/statistics/379046/worldwide-retail-e-commerce-sales/ (дата обращения 05.03.2021)

2. Бюро национальной статистики Казахстана // https://stat.gov.kz/official/industry/17/statistic/5 (дата обращения 05.03.2021)

3. The Saber story. A chance meeting on an airline flight that turned into the technology leader for the travel industry // Saber Corporation. Url: https://www.sabre.com/files/Sabre-History.pdf (date of access 05.03.2021)

4. Исследовательское агентство США еMarketer https://www.emarketer.com/content/global-ecommerce-saleswill-decelerate-this-year (дата обращения 05.03.2021)

5. The truth about online consumers: 2017 global online consumer report // KPMG International Limited. URL: https://assets.kpmg/content/dam/kpmg/xx/pdf/2017/01/thetruth-about-online-consumers.pdf (дата обращения 05.03.2021)

6. Ворона А.А. Маркетинговые инструменты при организации Интернет-торговли // Ученые записки СанктПетербургского имени В.Б. Бобкова филиала Российской таможенной академии. 2020. № 3 (75). С. 49-52.

7. Стеблюк Илья Юрьевич, Электронная коммерция в современном мире. Использование Pricing intelligence, «ИННОВАЦИИ И ИНВЕСТИЦИИ». № 1. 2021, стр. 52-55

8. Online share of retail sales in Great Britain 2010-2020Published by Daniela Coppola, Feb 15, $2021 \mathrm{https}$ ://www. statista.com/statistics/825461/proportion-of-retail-sales-made-online-great-britain-total/ (дата обращения 05.03.2021)

9. E-commerce share of retail sales in goods China 2014-2020 Published by Yihan Ma, Jan 27, 2021// https://www. statista.com/statistics/1129915/china-ecommerce-share-of-retail-sales/ (дата обращения 05.03.2021)

10. Share of e-commerce sales in total U.S. retail sales 2010-2020 Published by Daniela Coppola, Dec 2, 2020 // https:// www.statista.com/statistics/187439/share-of-e-commerce-sales-in-total-us-retail-sales-in-2010/ (дата обращения 05.03.2021)

11. Фу Цзао, Перспективные Пути Развития Прямых Продаж Международной Электронной Торговли между Китаем и Россией // экономика, политика, право. 2020. № 4, стр 44-59

12. UK Office for National Statistics // https://www.ons.gov.uk/businessindustryandtrade/retailindustry/timeseries/ j4mc/drsi (дата обращения 05.03.2021) 
13. E-commerce in the times of COVID-19, OECD report,7 October 2020 // http://www.oecd.org/coronavirus/policyresponses/e-commerce-in-the-time-of-covid-19-3a2b78e8/ (дата обращения 05.03.2021)

14. Информационный портал Параграф // https://online.zakon.kz/Document/?doc_id=32416273\#pos=3;-80 (дата обращения 05.03.2021)

15. Официальный информационный ресурс Премьер-Министра Республики Казахстан // https://primeminister. kz/ru/news/v-2019-godu-obem-pokupok-v-kazahstanskih-internet-magazinah-sostavil-422-mlrd-tenge (дата обращения 05.03.2021)

16. Анализ рынка розничной электронной коммерции в Республике Казахстан, опрос компании PwC // https:// www.pwc.kz/ru/publications/e-commerce-analysis/e-commerce-12m2020-12m2019.html (дата обращения 05.03.2021) 